\title{
FAKTOR-FAKTOR YANG BERHUBUNGAN DENGAN INFEKSI NOSOKOMIAL PADA PENGELOLA LIMBAH MEDIS PADAT (CLEANING SERVICE) DI RSUD BANGKINANG TAHUN 2016
}

\author{
Erma Kasumayanti \\ Dosen Prodi Sarjana Keperawatan FIK Universitas Pahlawan Tuanku Tambusai
}

\begin{abstract}
ABSTRAK
Penyakit infeksi masih merupakan penyebab utama tinginya angka kesakitan dan kematian di dunia. Salah satu jenis infeksi adalah infeksi nosokomial.Infeksi nosokomial adalah infeksi yang diperoleh pasien, pengunjung, dan petugas.Salah satu petugas yang rentan dengan infeksi nosokomial ini adalah pengelola limbah medis padat (cleaning service).Penelitian ini bertujuan untuk mengidentifikasi faktor-faktor yang berhubungan dengan infeksi nosokomial pada pengelola limbah medis padat diRSUD Bangkinang. Penelitian ini menggunakan metode analitik kuantitatif. Teknik sampel yang digunakan adalah total sampling, populasi dan sampel dalam penelitian ini berjumlah 40cleaning service. Pengumpulan data dilakukan dengan menggunakan lembar checklist dan kuesioner yang telah dilakukan uji validitas dan reliabilitas.Dari analisa bivariat juga didapatkanfaktor-faktor yang berhubungan dengan infeksi nosokomial adalah personal hygiene $(\mathrm{p}$ value $=0.002)$, pemakaian APD $(\mathrm{p}$ value $=0.011)$, imunisasi $(\mathrm{p}$ value $=0.001)$ dan pengetahuan $(\mathrm{p}$ value 0.003$)$. Rekomendasi bagi pihak RSUD Bangkinang agar lebih memperhatikan dan memberikan ketersediaan alat pelindung diri, penyuluhan, serta pelatihan bagi pengelola limbah medis yang bersifat dua arah dan praktik agar cleaning service lebih tahu dan siap dalam mencegah infeksi nosokomial.
\end{abstract}

Keywords : : infeksi nosokomial, pengelola limbah medis padat Bibliography : 38 (2003-2012)

\section{PENDAHULUAN}

Rumah sakit memiliki fungsi pemberian pelayanan dalam rangka mendiagnosis, mengobati dan menyembuhkan penderita sehingga didapatkan kondisi yang sehat dan bebas dari penyakit, (Sutrisnowati, 2004).

Dalam melakukan kegiatan pelayanan kesehatan, rumah sakit menggunakan berbagai bahan, energi, air, udara dan gas. Bahanbahan yang digunakan adalah bahan kimia dan bahan lain untuk keperluan layanan medis maupun non medis. Dalam pemakaian bahan tersebut sebagian digunakan, namun juga sebagian tersisa karena volume lebih, atau akibat lain seperti penanganan yang kurang baik sehingga dapat menyebabkan timbulnya limbah baik dalam bentuk padat, cair maupun gas (Pruss, 2005).

Limbah medis adalah limbah sarana medis yang habis setelah digunakan sebagai alat bantu diagnosis, pengobatan, prosedur dan tindakan medis atau perawatan pada pasien, misalnya kassa, plester, jarum suntik, set infus/botol infus, kantung darah, sarung tangan dan sebagainya. Limbah non medis adalah limbah hasil kegiatan rumah 
tangga rumah sakit (kantor/tata usaha, dapur, taman, gudang, rekam medis dan sebagainya), misalnya kertas, plastik, kaleng, sayur/buah yang terbuang, daun, ranting dan lain-lain (Darmadi, 2008). Tahap pemilahan kedua jenis limbah ini dilakukan mulai dari tempat sumber limbah, yakni unit perawatan/unit pelayanan medis (Djohan \& Halim, 2013).

Pengelolaan limbah rumah sakit adalah suatu upaya yang dilakukan terhadap limbah, mulai dari tahap pemilahan dan pengumpulan di tempat sumber, pengangkutan, penampungan hingga tahap pemusnahan (Djohan \& Halim, 2013). Peran cleaning service dalam pengelolaan limbah terletak pada tahap pemilahan (Indonesia Public Health Information, 2014). cleaning service harus memilah limbah medis dan limbah non medis serta menempatkannya pada wadah penampung berdasarkan jenis limbah dan/atau sesuai ketentuan yang ada di rumah sakit (Djohan \& Halim, 2013). Jika hal tersebut tidak sesuai dengan standarnya maka berdampak terjadinya infeksi nasokomial.

Infeksi nosokomial atau disebut juga Hospital Acquired Infection (HAI) adalah infeksi yang didapatkan dan berkembang selama pasien di rawat di rumah sakit (WHO, 2004). Sumber lain mendefinisikan infeksi nosokomial merupakan infeksi yang terjadi di rumah sakit atau fasilitas kesehatan setelah dirawat $2 \times 24$ jam. Sebelum di rawat, pasien tidak memiliki masa inkubasi. Infeksi nosokomial bukan merupakan dampak dari infeksi penyakit yang telah dideritanya. Pasien, petugas kesehatan, pengunjung dan penunggu pasien merupakan kelompok yang berisiko terjadinya infeksi nosokomial karena infeksi ini dapat menular dari pasien ke petugas kesehatan, dari pasien ke pengunjung atau keluarga ataupun dari petugas ke pasien (Prawiroharjo, 2004).

Suatu penelitian yang dilakukan oleh WHO (2009) menunjukkan bahwa sekitar $8,7 \%$ dari 55 rumah sakit dari 14 negara di Eropa, Timur Tengah, Asia Tenggara dan Pasifik terdapat infeksi nosokomial, khususnya di Asia Tenggara sebanyak $10 \%$. Survei prevalensi yang terbaru dilakukan WHO (2014), di 55 rumah sakit dari 14 negara yang mewakili 4 Kawasan WHO (Eropa, Timur Tengah, Asia Tenggara dan Pasifik Barat) menunjukkan ratarata $8,7 \%$ pasien rumah sakit mengalami infeksi nosokomial. Setiap saat, lebih dari 1,4 juta orang di seluruh dunia menderita komplikasi dari infeksi yang diperoleh di rumah sakit. Frekuensi tertinggi infeksi nosokomial dilaporkan dari rumah sakit di kawasan Timur Tengah dan Asia Tenggara $(11,8 \%$ dan $10,0 \%$ masing-masing), dengan prevalensi 7,7\% dan 9,0\% masing-masing di kawasan Eropa dan Pasifik Barat (WHO, 2013).

Sepuluh Rumah Sakit Umum (RSU) pendidikan di Indonesia pada tahun 2010 mencatat angka kejadian infeksi nosokomial yang terjadi sekitar 6-16\% dengan ratarata 9,8\% (Nugraheni, $d k k, 2012$ ). Rumah Sakit Umum Daerah (RSUD) Prof. Dr. W. Z. Johannes Kupang sebagai salah satu rumah sakit rujukan di Nusa Tenggara Timur (NTT) juga mencatat adanya infeksi nosokomial yang terjadi pada tahun 2014. Angka infeksi nosokomial yang terjadi pada bulan Februari 2014 adalah 0,17\%, pada 
bulan Maret 0,15\%, pada bulan Mei sekitar $0,04 \%$, pada bulan Juni terjadi peningkatan menjadi $0,69 \%$ (RSUD Kupang, 2014).

Saat ini angka kejadian infeksi nosokomial telah dijadikan salah satu tolok ukur mutu pelayanan rumah sakit. Berdasarkan Kepmenkes No 129 tahun 2008, standar kejadian infeksi nosokomial di rumah sakit < $1,5 \%$. Izin operasional sebuah rumah sakit bisa dicabut karena tingginya angka kejadian infeksi nosokomial. Bahkan pihak asuransi tidak mau membayar biaya yang ditimbulkan oleh infeksi ini (Darmadi, 2008).

Petugas pelayanan kesehatan dan pengelola limbah medis padat setiap hari dihadapkan kepada tugas yang berat untuk bekerja dengan aman dalam lingkungan yang membahayakan. Risiko pekerjaan yang umum dihadapi oleh petugas pelayanan kesehatan dan pengelola limbah medis padat adalah pemaparan terhadap patogen ini meningkatkan risiko mereka terhadap infeksi yang serius dan kemungkinan kematian (Pruss, 2005). Infeksi nosokomial pada pengelola limbah medis padat disamping mengurangi produktifitas kerja juga sangat membahayakan bagi pengelola limbah medis padat itu sendiri bahkan mengakibatkan kematian. (Nugraheni, $d k k, 2012$ ).

Pengelolaan limbah jenis ini mengacu Peraturan Pemerintah Nomor 18 Tahun 1999, tentang pengelolaan limbah bahan berbahaya dan beracun (B3). Sedangkan limbah padat non medis/domestik adalah limbah padat non infeksius akibat kegiatan pelayanan rumah sakit seperti sampah sisa makan pengunjung, sampah aktifitas kantor, aktifitas kantin, aktifitas dapur dan lainnya yang bisa dimasukkan dalam pengelolaan sampah kota (Kepmen LH, 2010). Diperkirakan secara nasional produksi limbah padat rumah sakit sebesar 376.089 ton/hari dan limbah cair $48.985,70$ ton/hari. Dengan besarnya angka limbah padat maupun cair yang dihasilkan oleh rumah sakit, dapat dibayangkan betapa besarnya kemungkinan potensi limbah rumah sakit mencemari lingkungan serta dalam menyebabkan kecelakaan kerja serta penularan penyakit jika tidak ditangani dengan baik (Dhani, 2011).

Dalam KEPMENKES No. 129 tahun 2008 ditetapkan suatu standar pelayanan minimal rumah sakit, termasuk didalamnya pelaporan kasus infeksi nosokomial untuk melihat sejauh mana rumah sakit melakukan pengendalian terhadap infeksi ini. Data infeksi nosokomial dari surveilans infeksi nosokomial di setiap rumah sakit dapat digunakan sebagai acuan pencegahan infeksi guna meningkatkan pelayanan medis bagi pasien (Kepmenkes RI, 2010).

Pelayanan Rumah Sakit sesuai fungsi diatas diharapkan tidak mengakibatkan gejala penularan kepada pengguna rumah sakit itu sendiri (infeksi). Penyakit infeksi merupakan penyebab utama tinginya angka kesakitan dan kematian di dunia. Mengingat rumah sakit terkait dengan kondisi yang rawan baik untuk pengelola maupun pengunjung serta pasiennya diperlukan pengelolaan yang sangat serius mengingat beberapa jenis kuman dapat tumbuh dan berkembang sesuai kondisi ideal yang dibutuhkan oleh jenis kuman tersebut. Untuk itu diperlukan upaya untuk pengendalian pertumbuhan dan 
perkembangan kuman antara lain dengan cara pengelolaan limbah yang mampu memusnahkan kuman agar tidak menimbulkan dampak bagi masyarakat rumah sakit maupun masyarakat luar rumah sakit. Upaya pengelolaan kuman penyebab penyakit tersebut dilakukan oleh satu tim yaitu tim pengendalian infeksi nosokomial (Sutrisnowati, 2004).

Banyak faktor yang mempengaruhi penularan infeksi nosokomial pada pengelolah limbah medis padat, diantaranya : personal hygiene, alat pelindung diri (APD), imunisasi, masa kerja/pengalaman kerja, riwayat penyakit sebelumnya dan pengetahuan (Kepmenkes RI, 2009).

Rumah Sakit Umum Daerah Bangkinang adalah rumah sakit yang tergolong tipe $\mathrm{C}$ berdasarkan SK Menkes Nomor : 551/Menkes/SK/VI/1996. Yang saat ini mempunyai 114 tempat tidur dengan Bed Acupation Rate (BOR) $56 \%$ (Profil tahun 2015).

$$
\text { RSUD }
$$

Bangkinang

mempunyai 40 orang cleaning service yang sekaligus bertugas sebagai pengelola limbah medis padat mulai dari pengumpulan, pengangkutan dan pemusnahan limbah medis padat termasuk operator incenerator. Berdasarkan data kasus kejadian infeksi nosokomial pada petugas cleaning service di RSUD Bangkinang didapatkan 2 orang yang terinfeksi hepatitis satu diantaranya pernah tertusuk jarum diruangan perawatan penyakit dalam ketika hendak membuang sampah benda tajam ke incenerator dan satu dari penderita TB paru karena terpapar penyakit selama bekerja di ruangan penyakit dalam karena ruangan penyakit dalam bergabung dengan ruangan penyakit paru.

Pada proses pengelolaan limbah medis padat, pengelola (cleaning service) kontak langsung dengan limbah medis padat sehingga kemungkinan terjadinya infeksi lebih besar dibandingkan dengan bagian lain. Oleh karena itu penelitian ini dilakukan pada pengelola limbah medis padat yaitu cleaning service.

Berdasarkan data dan fenomena uraian latar belakang di atas, penulis tertarik untuk meneliti tentang faktor-faktor yang berhubungan dengan kejadian infeksi nosokomial pada pengelola limbah medis padat (cleaning service) di RSUD Bangkinang tahun 2016".

\section{METODE}

Jenis penelitian ini adalah analitik kuantitatif dengan desain crosssectional.Penelitian ini dilakukan di RSUD Bangkinang.Penelitian ini dilakukan pada tanggal 25 Juli - 25 Agustus 2016. Populasi dalam penelitian ini adalah semua pengelola limbah medis padat (cleaning service) di RSUD Bangkinang yang berjumlah 40orang. Teknik pengambilan sampel yang digunakan pada penelitian ini menggunakan teknik total sampling. Alat pengumpulan data yang digunakan peneliti adalah lembar checklist dan kuesioner. Analisa data yang digunakan adalah univariat dan bivariat.

\section{HASIL PENELITIAN} Analisa Univariat

Hasil analisa univariat variable - variabel faktor- faktor yang berhubungan dengan infeksi nasokomial padapengelolalimbah medis padat(Cleaning Service) diketahui bahwa dari 40 cleaning 
service,didapatkansebagianrespond ensebanyak 18 (45\%)cleaning servicemenggunakantahapanperso nal hygieneyang tidakbaik,sebagianbesardarirespon densebanyak 24 (60\%)cleaning servicetidakmenggunakan APD secaralengkap, sebagiankecilrespondensebanyak 14 (35\%)cleaning servicetidakimunisasidenganlengk ap, sebagiankecildarirespondensebany $\begin{array}{lll}\text { ak } & 9 & (22,5 \%) \text { cleaning }\end{array}$ servicemengalamimasakerja yang baru, sebagiankecildarirespondensebany ak $15 \quad(37,5 \%) \quad$ cleaning servicepernahmemilikiriwayatpeny akit, sebagianrespondensebanyak 22 (55\%)cleaning servicememilikipengetahuan yang kurang, dansebagiankecildarirespondenseb anyak $\quad 13 \quad(32,5 \%)$ cleaning servicemengalamiinfeksinosokomi al.

\section{Analisa Bivariat \\ Dari hasil penelitian yang telah dilakukan maka diperoleh bahwadari 18 personal hygienetidakbaikyang tidakterjadiinfeksinosokomialsebany ak 7 (38,9\%) cleaning service dandari 22personal hygiene baikterdapat $(9,1 \%)$ cleaning service terjadiinfeksinosokomial.Hasilujist atisticdidapatkan $p$ value $=0.002$ maka secara statistik adahubungan yang signifikanantarapersonal hygienedengankejadianinfeksinosok omial.KemudiandiperolehPOR \\ $($ PrevalensiOdds Ratio $)=15.714$ artinyacleaning service yang personal hygieneyang tidakbaikmempunyairisiko $\quad 15.7$ kali \\ lebihtinggimengalamiinfeksinosok}

omialdibandingkandengancleaning service yang menggunakanpersonal

hygieneyang baik.

$$
\text { Dari } 24 \text { Penggunaan }
$$

APDtidaklengkap yang tidakterjadiinfeksinosokomialsebany ak $12 \quad(50 \%) \quad$ cleaning service, dandari 16 Penggunaan APDlengkapterdapat $1 \quad(26,3 \%)$ cleaning service terjadiinfeksinosokomial.Hasilujist atisticdidapatkan $p$ value = 0.011makadapatdisimpulkanadahub ungan yang signifikanantarapemakaian APDdengankejadianinfeksinosokom ial. KemudiandiperolehPOR = 15artinyacleaning service yang memakaian APDyang tidaklengkapmempunyairisiko 15 kali

lebihtinggimengalamiinfeksinosok omialdibandingkandengancleaning serviceyang menggunakan APD yang lengkap.

Dari 14 imunisasitidaklengkap yang tidakterjadiinfeksinosokomialsebany ak $4 \quad(28,6 \%) \quad$ cleaning service,dandari 16 imunisasilengkapterdapat 3 $(11,5 \%) \quad$ cleaning serviceterjadiinfeksinosokomial.Ha silujistatistikdidapatkan $p$ value = 0.001makadapatdisimpulkanadahub ungan yang signifikanantaraimunisasidengankej adianinfeksinosokomial.

KemudiandiperolehPOR = 19.167artinyacleaning serviceyang imunisasilengkapmempunyairisiko 19.167

kali lebihtinggimengalamiinfeksinosok omialdibandingkandengancleaning serviceyang imunisasilengkap.

Dari 9 masakerjabaru yang tidakterjadiinfeksinosokomialsebany ak $4 \quad(44,4 \%) \quad$ cleaning service, dandari 31 masakerja 
lamaterdapat $8(25,8 \%)$ cleaning serviceterjadiinfeksinosokomial.Ha silujistatisticdidapatkan pvalue = 0.12

makadapatdisimpulkantidakadahubu ngan yang signifikanantaramasakerjadengankej adianinfeksinosokomial.

KemudiandiperolehPOR $=3.594$ artinyacleaning serviceyang masakerjabarumempunyairisiko

3.594

kali

lebihtinggimengalamiinfeksinosok omialdibandingkandengancleaning serviceyang masakerja lama.

Dari

memilikiriwayatpenyakit yang tidakterjadiinfeksinosokomialsebany ak $12 \quad(80 \%) \quad$ cleaning service, dandari

25tidakmemilikiriwayatpenyakitter dapat $10 \quad(40 \%) \quad$ cleaning serviceterjadiinfeksinosokomial.Ha silujistatisticdidapatkan $p$ value = 0.298makadapatdisimpulkantidakad ahubungan yang signifikanantarariwayatdengankejad ianinfeksinosokomial.

KemudiandiperolehPOR = 0.375artinyacleaning serviceyang memiliki

riwayatpenyakitmempunyairisiko0 .3754 kali

lebihtinggimengalamiinfeksinosok omialdibandingkandengancleaning serviceyangtidakmempunyairiway atpeyakit

Dari 22 pengetahuankurang yangtidakterjadiinfeksinosokomialse

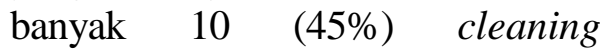
service, dandari 18 pengetahuanbaikterdapat $1(5,6 \%)$ cleaning

serviceterjadiinfeksinosokomial.Ha silujistatistikdidapatkan $p$ value = 0.003makadapatdisimpulkanadahub ungan

yangsignifikanantarapengetahuande ngankejadianinfeksinosokomial.Ke mudiandiperolehPOR 20.400artinyacleaning serviceyang berpengetahuankurangmempunyair isiko $20.4 \quad$ kali lebihtinggimengalamiinfeksinosok omialdibandingkandengancleaning serviceyang berpengetahuanbaik.

\section{PEMBAHASAN}

1. Hubungan

Hygienedengan

Personal

Nosokomial pada Pengelola

Limbah Medis Padat (Cleaning

Service)di RSUD Bangkinang

Tahun 2016

Hasil

penelitian

menunjukkanbahwa dari 18

responden yang Personal Hygiene tidak baik tetapi tidak terjadi infeksi nosokomial sebanyak $7 \quad(38,9 \%)$ cleaning service, dan dari 22 responden Personal Hygiene baik terdapat $2(9,1 \%)$ cleaning serviceterjadi infeksi nosokomial, hasil ini menyatakan ada hubungan antara personal hygienedengan kejadian infeksi nosokomial pada pengelola limbah medis padat (cleaning service) di RSUD Bangkinang $(p$ value = $0.002<0.05)$.Hasil penelitian ini sejalan dengan penelitian yang dilakukan Sumaryadi (2011), bahwa ada hubungan yang signifikanantara personal hygienedengan kejadian infeksi nosokomial pada pengelola limbah medis padat.

Menurut Potter dan Perry (2005), sikap seseorang melakukan personal hygienedipengaruhi oleh sejumlah faktor antara lain: 1) Citra tubuh: Citra tubuh merupakan konsep subjektif seseorang tentang penampilan fisiknya; 2) Praktik sosial: Kelompok-kelompok sosial wadah seorang klien berhubungan dapat mempengaruhi praktik hygiene pribadi; 3) Status sosio-ekonomi: sumber daya ekonomi seseorang 
mempengaruhi jenis dan tingkat praktik kebersihan yang digunakan;

Pengetahuan:Pengetahuan tentang pentingnya hygiene dan implikasinya bagi kesehatan mempengaruhi praktik hygiene; 5) Variabel kebudayaan: Orang dari latar kebudayaan yang berbeda mengikuti praktik keperawatan diri yang berbeda pula; 6) Pilihan pribadi: Setiap klien memiliki keinginan individu dan pilihan tentang kapan untuk mandi, bercukur, dan melakukan perawatan rambut; 7) Kondisi fisik: Orang yang menderita penyakit tertentu (misal Kanker tahap lanjut) atau menjalani operasi sering kali kekurangan energi fisik atau ketangkasan untuk melakukan hygiene pribadi.

Hasil penelitian di atas didapatkan bahwa ada sebanyak 11 (61.1\%) cleaning serviceyang tidak baik dalam personal hygienemengalami infeksi nosokomial.Hal ini ditunjukkan pada instrumen penelitian bahwa responden tidak melakukan tahapan-tahapan cara mencuci tangan yang tidak benar, masih terdapat sabun yang tidak dibilas dengan bersih, dan masih ada yang tidak mengeringkan tangan setelah mencuci tangan.

Hal ini juga didukung oleh Prihatini (2007), bahwa karakteristik perawat tidak tepat atau tidak prosedural dalam personal hygiene ditandai dengan tangan yang masih kelihatan kotor, masih terlihat basah, adanya sisa sabun pada tangan, dan terlihat pakaian yang kotor akibat terkena cairan darah atau kimia. Oleh sebab itu, penting bagi cleaning service dalam menjaga personal hygiene yang tepat sehingga tidak terjadi atau meminimalkan penyakit.

2. Hubungan Penggunaan APD dengan Infeksi Nosokomial pada Pengelola Limbah Medis Padat (Cleaning Service)di RSUD Bangkinang Tahun 2016

Alat Pelindung Diri atau APD adalah suatu alat yang mempunyai kemampuan untuk melindungi seseorang yang fungsinya mengisolasi sebagian atau seluruh tubuh dari potensi bahaya di tempat kerja (PER.08/MEN/VII/2010, pasal 1, Menteri tega Kerja dan Transmigrasi).

Berdasarkan Hasil penelitian didapatkan bahwa dari 24 Penggunaan APD tidak lengkap yang tidak terjadi infeksi nosokomial sebanyak 12 (50\%), kurang lengkapnya pemakaian APD yang digunakan oleh cleaning service, hal ini ditunjukkan pada instrumen bahwa, terdapat cleaning service yang tidak menggunakan baju pelindung sesuai, dan masih terlihat tidak memakai sepatu dalam berkerja.

Hasil penelitian ini sejalan yang dilakukan oleh Sumaryadi (2011), menunjukkan sebagian besar responden $(57.1 \%)$ cleaning service tidak menggunakan APD secara lengkap. Hal ini disebabkan kurangnya tersedia alat pelindung diri yang digunakan, serta kurangnya motivasi dari cleaning service dalam menggunakan alat pelindung diri.Hal ini sangat penting untuk diperhatikan, bahwa pemakaian APD yang lengkap akan mencegah atau menghindari risiko terhadap kuman, bakteri, serta virus yang menyebabkan penyakit. Bagi manajemen rumah sakit sangat diperhatikan akan ketersedian APD serta adanya sosialisasi akan pentingnya pemakaian APD yang lengkap.

Penelitian Syaaf (2008), diketahui bahwa yang berhubungan dengan prilaku 
penggunaan APD antara lain pengetahuan, pelatihan, sikap, motovasi, komunikasi, ketersediaan APD, pengawasan, hukuman, dan penghargaan. Penggunaan alat pelindung diri sudah seharusnya menjadi keharusan. Hal ini disebabkan masih lemahnya kedisiplinan dan kesadaran para perkerja.Kegiatan pencegahan penularan infeksi di rumah sakit melibatkan semua petugas kesehatan yang berada di lingkungan rumah sakit termasuk cleaning service. Salah satu elemen penting yang dapat menghindari infeksi nosokomial yaitu dengan menggunakan alat pelindung diri (APD) diantaranya sarung tangan, masker,pakaian pelindung diri, sepatudan topi untuk mengelola jarum dan alat tajam untuk mencegah perlukaan dan mengelola limbah rumah sakit dan sanitasi ruangan (Depkes RI, 2007).

Peneliti berasumsi yang berdasarkan kuesioner, 24 responden yang menggunakan APD tidak lengkap, ada 12 orang tidak terjadi infeksi nosokomial, ini dikarenakan oleh responden mempunyai personal hygiene yang baik sebanyak $8 \quad(66,7 \%)$ responden, imunisasi lengkap sebanyak $11(91,7 \%)$ responden, tidak memiliki riwayat penyakit sebanyak $7(58,3 \%)$ responden, bekerja pada kategori lama sebanyak 9 (75\%) responden, dari segi pengetahuan responden memiliki pengetahuan baik yaitu 10(83,3\%) responden. Sedangkan 16 responden yang menggunakan APD secara lengkap, ada 1 orang terjadi infeksi nosokomial, ini dikarenakan oleh personal hygiene yang tidak baik seperti tidak mencuci tangan sebelum melakukan tindakan dan tidak mencuci tangan sesuai tahapan secara benar, responden tidak imunisasi lengkap seperti imunisasi TBC dan tetanus, responden bekerja selama 2 tahun, dalam segi pengetahuan responden memiliki pengetahuan kurang tentang limbah medis dan cara mencuci tangan. Oleh karena itu penggunaan APD yang lengkap harus selalu diterapkan oleh pengelola limbah medis padatuntuk menghindari agar tidak melukai pengelola sendiri.

\section{Hubungan Imunisasi dengan Kejadian Infeksi Nosokomial pada Pengelola Limbah Medis Padat (Cleaning Service)di RSUD Bangkinang Tahun 2016}

Imunisasi adalah suatu cara untuk meningkatkan kekebalan seseorang secara aktif terhadap suatu penyakit, sehingga bila kelak terpapar dengan penyakit tidak akan menderita penyakit tersebut (Mulyani, 2013 dalam Faradilla, 2015).Imunisasi yang dianjurkan untuk petugas kesehatan dan petugas pengelola limbah medis adalah hepatitis B, tetanus, dan mantouxtest untuk melihat apakah ada infeksi TB sebelumnya.

Berdasarkan Hasil penelitian menunjukkan 14 imunisasi tidak lengkap yang tidak terjadi infeksi nosokomial sebanyak $4 \quad(28,6 \%)$ cleaning service. Hal ini menunjukkan bahwa responden yang imunisasi secara tidak lengkap disebabkan kurangnya pengetahuan akan pentingnya imunisasi.Kurang kesadaran serta pengetahuan responden akan imunisasi ini sangat berpengaruh akan mudahnya timbul penyakit. Hal ini sejalan penelitian yang dilakukan oleh Sumaryadi (2011), bahwa responden yang tidak melakukan imunisasi disebabkan minimnya pengetahuan yang diperoleh. Hasil penelitian juga diperoleh bahwa didapatkan usia yang tidak melakukan imunisasi di atas 30 tahun, hal ini sangat penting bagi rumah sakit untuk memperhatikan dan memberikan anti imun terhadap cleaning service yang belum lengkap agar terhindar dari penyakit, karena cleaning service merupakan human yang kontak langsung dengan limbah bekas dari rumah sakit. 
Menurut asumsi peneliti bahwa fasilitas kesehatan harus memiliki program pencegahan dan pengendalian infeksi bagi petugas kesehatan termasuk pengelolah limbah medis padat.

4. Hubungan Masa Kerja dengan Kejadian Infeksi Nosokomial pada Pengelola Limbah Medis Padat (Cleaning Service)di RSUD Bangkinang Tahun 2016

Hasil penelitian menunjukkan bahwa dari 9 masa kerja baru yang tidak terjadi infeksi nosokomial sebanyak 4 $(44,4 \%)$ cleaning service, dan dari 31 masa kerja lama terdapat $8(25,8 \%)$ cleaning serviceterjadi infeksi nosokomial. Hasil penelitian menyatakan tidak ada hubungan antara masa kerjadengan kejadian infeksi nosokomial pada pengelola limbah medis padat (cleaning service) di RSUD Bangkinang, ini dibuktikan dengan hasil SPSS $(p$ value $=0.12>0.05$ ).

Menurut asumsi peneliti berdasarkan kuesioner, 9 responden yang masa kerja baru, ada 4 orang tidak terjadi infeksi nosokomial, ini dikarenakan oleh responden mempunyai personal hygiene yang tidak baik dan memiliki riwayat penyakit masing-masing sebanyak 1 (25\%) responden, imunisasi tidak lengkap sebanyak 3 (75\%) responden, dari segi pengetahuan responden memiliki pengetahuan baik yaitu $3(75 \%)$ responden. Sedangkan 31 responden yang masa kerja lama, ada 8 orang terjadi infeksi nosokomial, ini dikarenakan oleh personal hygiene yang tidak baiksebanyak $8(100 \%)$ responden, seperti tidak mencuci tangan dengan air dan sabun sebelum melakukan tindakan, tidak mencuci tangan sesuai tahapan secara benar dan tangan tidak dikeringkan setelah mencuci tangan,penggunaan APD tidak lengkap dan imunisasi tidak lengkap masingmasing sebanyak $7(87,5 \%)$ responden yaitu baju pelindung yang digunakan tidak menutupi seluruh bagian tubuh, tidak menggunakan sepatu yang menutupi kaki, tidak imunisasi TBC dan hepatitis Bdalam segi pengetahuan responden memiliki pengetahuan kurang tentang limbah medis sebanyak 7 $(87,5 \%)$ responden. Jadi seorang pekerja tidak dinilai dari masa kerjanya, setiap perkerja baik yang baru maupun lama dapat melakukan kesalahan, dan tidak menjamin akan terhindarnya dari wabah penyakit menular. Kesalahan-kesalahan dapat terjadi baik dari perkerja yang masih sangat baru bahkan perkerja yang sudah sangat lama.

Hasil penelitian ini sejalan dengan penelitan yang dilakukan oleh Sumaryadi (2011), bahwa masa kerja tidak ada hubungannya dengan kejadian infeksi nosokomial pada perkerja di RSUD Bangkinang.Hasil penelitian Widajati (2008) juga membuktikan bahwa tidak ada pengaruh masa kerja dengan kejadian infeksi nosokomial pada petugas di RSU Dr. Soetomo.

\section{.5.Hubungan Riwayat Penyakit dengan Kejadian Infeksi Nosokomial pada Pengelola Limbah Medis Padat (Cleaning Service)di RSUD Bangkinang Tahun 2016}

Hasil penelitian menunjukkan bahwa dari 15 memiliki riwayat penyakit yang tidak terjadi infeksi nosokomial sebanyak 12 (80\%) cleaning service, dan dari 25 tidak memiliki riwayat penyakit terdapat $10(40 \%)$ cleaning serviceterjadi infeksi nosokomial. Hasil penelitian menyatakan tidak ada hubungan antara riwayatpenyakit dengan kejadian infeksi nosokomial pada pengelola limbah medis padat (cleaning service) di RSUD Bangkinang dengan $p$ value $=0.298>0.05$.

Peneliti berasumsi bahwa seseorang pernah mengalami riwayat penyakit memiliki tingkat antisipasi dalam pengelolaan limbah medis padat lebih baik dan lebih protektif dalam melaksanakan tugas.Hal ini didukung melalui hasil instrumen bahwa dari 15 responden yang memiliki riwayat penyakit hanya di temukan 3 responden 
yang memiliki riwayat penyakit mengalami infeksi nosokomial. Hal ini diperkuat dengan hasil observasi yang didapat bahwa 12 responden yang memilki riwayat penyakit melakukan personal hygiene dengan baik dan menggunakan APD dengan lengkap.

\section{Hubungan Pengetahuan dengan Infeksi Nosokomial pada Pengelola Limbah Medis Padat (Cleaning Service) di RSUD Bangkinang Tahun 2016}

Hasil penelitian menunjukkan bahwa dari 22 pengetahuan kurang yang tidak terjadi infeksi nosokomial sebanyak $10(45 \%)$ cleaning service, dan dari 18 pengetahuan baik terdapat 1 $(5,6 \%)$ cleaning serviceterjadi infeksi nosokomial. Hasil ini menyatakan ada hubungan antara pengetahuandengan kejadian infeksi nosokomial pada pengelola limbah medis padat (cleaning service) di RSUD Bangkinang dengan $p$ value $=0.003<0.05$.

Hasil penelitian ini menunjukkan bahwa masih banyak cleaning service yang masih memiliki pengetahuan rendah dan sedang.Hal ini menunjukkan bahwa cleaning service belum memiliki pengetahuan yang maksimal tentang limbah. Banyak faktor yang menyebabkan rendahnya pengetahuan seseorang, menurut Machfoedz (2008) diantaranya: 1) Kesadaran pribadi yang kurang untuk memiliki keinginan tumbuh dan maju,.2) Intelijensia (IQ) kurang, kekurangan dalam hal intelejensia akan menyebabkanpengetahuan kurang. 3) Rendahnya motivasi pribadi.

Perilaku petugas kesehatan khususnya petugas medis merupakan salah satu faktor yang mempengaruhi upaya pencegahan infeksi nosokomial. Salah satu perilaku yang mampu mencegah infeksi nosokomial termasuk meminimalisir jumlah bakteri yang ada di udara di rumah sakit adalah penerapan universal precaution (Depkes RI, 2007).

Hasil penelitian menunjukkan bahwa ada sebanyak $12(54.5 \%)$ cleaning service yang memiliki pengetahuan kurangmengalami infeksi nosokomial, sedangkan diantara cleaning serviceyang memiliki pengetahuan baik, ada $1(5.6 \%)$ mengalami infeksi nosokomial.

Hasil penelitian ini ada kesamaan dengan penelitian yang dilakukan oleh Jasmawati (2012) tentang hubungan pengetahuan dengan praktik petugas limbah didapatkan bahwa dari 34 responden sebagian besar responden $(72.7 \%)$ yaitu 8 responden memiliki pengetahuan buruk dengan praktik yang kurang baik, dan sebagian kecil responden $(27.3 \%)$ yaitu 3 responden memiliki pengatahuan baik dengan praktik yang kurang baik.

Menurut

penelitipengetahuan responden tentang pengolahan sampah dibangun berdasarkan pada kemampuan berfikir sesuai dengan kenyataan yang responden lihat dan temukan dilingkungan sekitar responden berada.Pengetahuan seseorang berpengaruh dalam proses terjadinya penularan infeksi nosokomial karena kemampuan berpikir sangat diperlukan saat menghadapi suatu kejadian atau suatu masalah, sehingga sangat diperlukan tindakan yang tepat terutama dalam mengelola limbah medis padat.

\section{KESIMPULAN DAN SARAN}


Dari hasil penelitian dapatdisimpulkan bahwa:

1. Sebagian respondenmemilikipersonal hygiene yang tidakbaik.

2. Sebagian besar responden menggunakan APD yang tidak lengkap.

3. Sebagiankecilrespondenmemili kiimunisasitidaklengkap.

4. Sebagianbesarrespondenmemili kimasakerja lama $\geq 1$ tahun.

5. Sebagiankecilrespondenmemili kiriwayatpenyakit.

6. Sebagianrespondenmemilikipen getahuankurang.

7. Sebagiankecilrespondenmengal amikejadianinfeksinosokomial.

8. Ada hubunganantarapersonal hygienedengankejadianinfeksino sokomialdi RSUD Bangkinang.

9. Ada hubunganantarapemakaian APD

dengankejadianinfeksinosokomia ldi RSUD Bangkinang.

10. Ada

hubunganantaraimunisasidengan kejadianinfeksinosokomialdi RSUD Bangkinang.

11. Tidakadahubunganantaramasake rjadengankejadianinfeksinosoko mialdi RSUD Bangkinang.

12. Tidakadahubunganantarariwayat penyakitdengankejadianinfeksino sokomialdi RSUD Bangkinang.

13. Ada hubunganantarapengetahuandeng ankejadianinfeksinosokomialdi RSUD Bangkinang.

\section{Saran}

Adapun saran yang dapat diberikan berdasarkan hasil penelitian adalah sebagai berikut

a. BagiManajemenRSUD

Bangkinang

1) Manajemenmemberikank etersediaanalatdanpelatih anbagipengelolalimbahm edisagar cleaning service lebihtahudansiapdalamm encegahinfeksinosokomi al.

2) Meningkatkan program keselamatankerja pegawai terutamacleaning serviceyang selaluberhadapandengan

risikotertularpenyakit yang tinggi, sertamemantausecara berkala

kesehatanpengawaicleaning

service minimal 2 kali dalamsetahun,

sehinggainfeksinosokomialdapat dideteksidanditanganisecaracepat

b. BagiCleaning Service RSUD Bangkinang

1) Memanfaatkanwaktuseca raefektifdalammenyelesai kantugas yang dibebankan agar tidakterjadipenumpukanp ekerjaansehinggadapatsel esaitepatpadawaktudantid akterburuburudalammenyelesaikan pekerjaan.

2) Meningkatkankesadarana kanbahayarisikodaripenul aranpenyakit(infeksinoso komial) dengan melakukan personal hygiene yang baik, penggunaan APD yang lengkap

\section{DAFTAR PUSTAKA}

Arikunto. (2006). Prosedur Penelitian. Jakarta : Rineka Cipta

Budiman. (2011). Penelitian Kesehatan. Bandung: PT Refika Aditama.

Dahlan, M.S. (2008). LangkahLangkah Membuat Proposal Penelitian Bidang Kedokteran dan Kesehatan, Edisi I. Jakarta: Sagung Seto. 
Darmadi, S. (2008). Infeksi Nosokomial

Problematika

dan

Pengendaliannya.

Jakarta,

Salemba Medika.

Depkes

RI.(2009).

PedomanPencegahandanPenge ndalianInfeksi $d i$

RumahSakitdanFasilitasPelaya nanKesehatanLainnya, Jakarta.

Dhani, M. (2011). Kajian Pengelolaan Limbah Padat Jenis B3 di Rumah Sakit Bhayangkara Surabaya. Surabaya.

Djohan dan Halim. (2013). Pengelolaan Limbah Rumah Sakit. Jakarta: Salemba Medika.

Faradilla, G. (2015).

MakalahImunisasiDasar.

Diambiltanggal 16 Agustus

2016

darihttps://gestyfaradilla94.wo rdpress.com. Hidayat, Aziz Alimul. (2011).
MetodePenelitian Keperawatan Dan Teknik Analisa Data. Jakarta: Selemba Medika.

Jasmawati.(2012).

HubunganRiwayatPenyakitDen ganKejadianInfeksiNosokomial Di RumahSakitUmum Daerah WahabSjahranieSamarinda.

Johanis. (2010). Kemanakah Jarum Suntik Setelah

Dipakai?.http://forum.upi.edu/i ndex.php?topic=12665.0, diakses tanggal 22 April 2016

Kepmenkes RI.

(2009).PengelolaanLimbahRum ahSakit, Jakarta

KepmenkesRI.(2010).

PedomanTeknisSaranadanPras
aranaRumahSakitKelas

$C$, Jakarta.

Kepmenkertrans

RI.(2010). AlatPelindungDiri.Jakarta.

Machfoedz. (2008). Metodologi Penelitian. Yogyakarta: Fitra Maya

Mariana, N. (2009). Faktor-Faktor yang

BerhubungandenganPenggun aan APD

padaPetugasBagianPengump ulSampah di RSUD

ArifinAchmadPekanbaru.

Notoatmodjo, Soekidjo.(2003).

IlmuKesehatanMasyarakat

Prinsip-PrinsipDasar.

Jakarta: PT RinekaCipta. (2007).

Promosikesehatan\&IlmuPrila $k u$. Jakarta: RinekaCipta.

Nugraheni,

dkk.(2012).AngkaKejadianInfe ksi Nosocomial di RSUD

Kupang, NTT. Di

ambiltanggal 4 april 2016.

Nursalam.(2003).

Konsep \&penerapanmetodolog

illmuKeperawatan.Jakarta:

SelembaMedika.

Potter \& Perry. (2005).

BukuPanduanKebutuhanDasa

rManusiaUntukPerawat,

Jakarta: EGC

PP No 18 Tahun 1999. Pengelolaan Limbah Bahan Berbahaya Dan Beracun, Jakarta.

PP No 085 Tahun1999. Perubahan PP

No 18 Tahun 1999.

TentangPengelolaan Limbah

Bahan Berbahaya Dan

Beracun, Jakarta. 
Pratiknya, AW. (2011). Dasar-dasar Metodologi Penelitian Kedokteran dan Kesehatan. Jakarta: Rajawali Press

Prawiroharjo, S. (2004). Panduan Pencegahan Infeksi untuk Fasilitas Pelayanan Kesehatan dengan Sumber Daya Terbatas. Jakarta: Bina Pustaka.

Profil. (2015). RumahSakitUmum Daerah Bangkinang

Pruss, A. (2005). PengelolaanAmanLimbahlaya nanKesehatan.Jakarta.

Riani, L.A. (2011). Budaya Organisasi. Yogyakarta: Graha Ilmu

Riyanto, Agus (2011). PengolahandanAnalisis Data Kesehatan.Yogyakarta: NuhaMedika.

Saghita, E.P. (2011).

TinjauanPengelolaan (Limbah B3), Padat di RSUD ArifinAchmadProvinsi Riau. Pekanbaru: Program SarjanaStikes Hang TuahPekanbaru.

Sujarweni, V. Wiratna.(2014). MetodologiPenelitianKeperaw atan. Yogyakarta: Gava Media

Sumaryadi, Engky.(2011).

GambaranFaktor-Faktor yang MempengaruhilnfeksiNosoko mial di RS

ProvinsiHasanSadikin Bandung.JurnalManajemen\& BisnisPadjajaran Vol. 3, No. 1

Suryani, F. (2011).FAktor-Faktor yang Berhubungandengan Dermatitis KontakpadaPerkerjaBagian Processing dan Filling, PT
Cosmar Indonesia.Tanggerang

Selatan. Jakarta:

FakultasKedokteran,

UniversitasSyarifHidayatullah.

Sutrisnowati, (2002). Pengelolah Limbah Padat Infkesius Rumah Sakit PT Pupuk KALTIM. Semarang: Program Pasca Sarjana, Universitas Diponogoro.

UU No 32 Tahun 2009. Perlindungan dan Pengelolaan Lingkungn Hidup, Jakarta

UU No 1 Tahun 1970.Keselamatan Kerja, Jakarta

WHO,

(2013).AngkaInfeksiNosokomi alMenurut WHO. Di ambiltanggal22 April 2016 darihttp://www.who.com.

Yulianto, B (2008). Hubungan antara Pengetahuan Perawat Tentang Infeksi Nosokomial dengan Prilaku Pencegahannya di Rumah Sakit Awal Bross Pekanbaru. Program Sarjana Ilmu Kesehatan Universitas Indonusa Eka Unggul Jakarta. 